\title{
NUDOS CRÍTICOS EN EL EJERCICIO DE LA ANTROPOLOGÍA FEMINISTA EN CHILE: CONSTRUCCIÓN DE CONOCIMIENTOS E INSTITUCIONALIZACIONN DEL FEMINISMO
}

\section{ARELI ESCOBAR SALAZAR ${ }^{\star}$, PAULA SANTANA NAZARIT** \& TATIANA ARAYA TORO***}

\section{Introducción}

En el presente texto se reflexiona sobre la antropología feminista en el Chile actual desde una mirada que recoge las voces de diversas mujeres que participaron en uno de los simposios del último Congreso Chileno de Antropología y el transitar de las autoras de lo que ha sido esta línea disciplinaria. Formamos parte de un proceso que comienza a fines de la década de 1980 con la creación del colectivo El Taller en la Escuela de Antropología de la Universidad Austral de Chile, uno de los primeros espacios formados por mujeres estudiantes de antropología y otras carreras de ciencias sociales y cuyo propósito era promover los estudios sobre las mujeres y cuestionar el androcentrismo en la disciplina desde una perspectiva feminista. En ese momento se desarrolla una amplia producción de estudios de género en el país y se crean asignaturas, posgrados y centros de investigación dedicados a estas temáticas en algunas universidades. El contexto histórico que acompañó aquella época fue el término formal de la dictadura militar y el comienzo de gobiernos democráticos tutelados por la
Constitución política del régimen saliente. El feminismo, en ese marco, aún actuaba en la clandestinidad y se debatía entre la autonomía y la participación institucional.

Hoy, al contrario, las nuevas generaciones de antropólogas, inspiradas en corrientes críticas del feminismo, han vivido en un ambiente de efervescencia y masividad de esta corriente, que se manifiesta con fuerza en contra de la violencia hacia las mujeres y una amplia gama de injusticias.

En el marco del $X$ Congreso Chileno de Antropología "Repensando desigualdades y diferencias en la convivencia sociocultural entre distintos", realizado en Temuco entre el 8 y el 12 de enero de 2019, organizamos el Simposio "Antropología feminista en clave decolonial y anticapitalista: sembrando vinculaciones entre academia y movimiento" impulsadas por el desafío de realizar un análisis crítico respecto de los aportes y las brechas entre la antropología feminista y el movimiento desde los enfoques teóricos radical, decolonial y anticapitalista. Este Simposio reunió doce ponencias

\footnotetext{
* Dra. en Antropología Social y Cultural, Dra. en Sociedad y Cultura. Antropóloga feminista, Concepción, Chile. Correo-e: areli21@gmail.com

${ }^{\star \star}$ Dra. en Ciencias con especialidad en Antropología Médica. Feminista autónoma. Valparaíso, Chile. Correo-e: paulasantanazarit@gmail.com

${ }_{* \star *}$ Mg. Desarrollo Rural. Antropóloga feminista, Valdivia, Chile. Correo-e: tatianaarayat@gmail.com
} 
que, de acuerdo con los contenidos abordados, organizamos en tres ejes centrales: sujetas subalternas y resistencias; Estado e institucionalidad, y construcción de conocimientos. En concordancia con la crítica planteada al formato de la academia como un espacio que solo valida el conocimiento positivista, realizamos como evento alternativo de cierre de este Simposio, un Foro/debate, en un espacio fuera del Congreso, al cual invitamos a organizaciones feministas del Wallmapu y a antropólogas feministas que habían expuesto en simposios similares. Ambos espacios nos permitieron reencontrarnos a antropólogas feministas de diversas generaciones, lo que facilitó un diálogo entre distintas, necesario para una apuesta disciplinaria y política en común.

Con la intención de dar continuidad a este espacio de reflexión colectiva sobre los nudos de la antropología feminista, organizamos un simposio en el marco del VI Congreso de la Asociación Latinoamericana de Antropología (ALA), con sede en Montevideo, Uruguay, que dada la contingencia sanitaria se realizó virtualmente entre el 24 y el 27 de noviembre de 2020. Por último, el 8 de marzo de este año se publicó un libro en formato virtual con la sistematización del Simposio de 2019.

Como parte de este proceso, nos propusimos como objetivo para este ensayo dar cuenta de los nudos y reflexiones críticas de un grupo de antropólogas feministas chilenas que dialogaron en el Simposio buscando respuestas a las siguientes interrogantes: ¿cuáles son los nudos de la antropología feminista de este último período en Chile?, ¿qué reflexiones están realizando las nuevas generaciones de antropólogas feministas?, ¿cómo nos vinculamos con la institucionalidad académica y estatal?, ¿de qué forma se construye un conocimiento situado fuera de la academia?

El documento aborda, en un primer momento, los cuestionamientos al enfoque de género y su despolitización por parte de la academia y de la nueva institucionalidad en los gobiernos de la posdictadura. El segundo punto trata la construcción de conocimientos, tanto desde la crítica a la academia formal como de la producción de saberes desde el feminismo. Como cierre, se presentan reflexiones que sintetizan las ideas fuerza de la antropología feminista en el Chile actual.

\section{Género e institucionalización del feminismo}

El enfoque o perspectiva de género, o simplemente "el género", es utilizado de diversas formas por las trabajadoras feministas de las ciencias sociales. En el Simposio primó una visión crítica sobre su impacto en las pretensiones de cambios sustantivos en la vida de las mujeres. A veces de manera confusa se ocupa para referirse indistintamente a las mujeres 0 a la identidad de género, en consonancia con la actual disputa ideológica, presente tanto al interior como fuera del movimiento feminista sobre el sujeto político mujer ${ }^{1}$. Asimismo, se cuestiona la lógica binaria, de por sí opuesta y excluyente, que impone el género en las relaciones sociales, crítica que el feminismo hace tempranamente al esencialismo del comportamiento social de mujeres y hombres, pero que va a adquirir otros matices y va a ser fundamental en el pensamiento feminista decolonial, que le atribuye a la modernidad colonial la exacerbación de la construcción de las jerarquías patriarcales (Lugones, citado en Mignolo, 2011; Segato, 2013). Vinculado 
a ello, aparece una crítica a la inclusión de sujetos subordinados como estrategia institucional, sin mayor profundización, expresada con frecuencia en la simple expresión numérica de mujeres y hombres, y ahora también de identidades de género, lo que desdibuja los objetivos políticos que persigue el feminismo, el cual apunta a la transformación de un sistema estructuralmente injusto.

Hace al menos dos décadas que se le atribuye al género la despolitización del feminismo que, a través de su ingreso a la academia y al Estado, se convirtió en una herramienta técnica para generar ciertos cambios formales y discretos, más bien orientados a cumplir con estándares internacionales que a trastocar la condición de subordinación de las mujeres. Por esto mismo, se tiende a aplicar mecánicamente enfoques y conceptos vigentes en otros países, pero que no necesariamente responden a la realidad local o que no han sido suficientemente socializados ${ }^{2}$. La tecnificación del género ha construido un discurso superficial sobre las desigualdades y diferencias entre los sexos, que antepone las categorías a la experiencia concreta de las mujeres y sus realidades. El enfoque de género, se convierte, así, en un conocimiento "experto", escindido de la experiencia personal y corporal, que expropia las voces y el protagonismo de las mujeres, quienes, en esta relación asimétrica, son "beneficiarias".

La amplia instalación del género está vinculada a un contexto histórico determinado. En la década de 1980, las mujeres toman conciencia de su propia opresión en pleno régimen dictatorial, en medio de la resistencia a la represión, el exterminio de militantes de izquierda y de luchadoras(es) populares y de una aguda crisis económica que fue enfrentada con organiza- ción social de base, espacios todos donde las mujeres fueron protagónicas. El feminismo irrumpió en las organizaciones mixtas y tomó, en principio, el camino de la autonomía, pero con el advenimiento de la institucionalidad civil se vio debilitada, ya que un sector de ese feminismo optó por fortalecer un movimiento autónomo y otro por participar de la nueva institucionalidad (Pisano \& Franulic, 2009). Con la progresiva institucionalización de la práctica política feminista, el género ocupó parte importante de la teorización de la condición de las mujeres desde la década de 1990. En este proceso se fue vaciando progresivamente de su contenido político mientras que feministas en la academia y en el Estado masificaban además su uso, lo que permeó también en el feminismo activista, que es justamente de donde provienen las críticas más consistentes.

Se señala como uno de los problemas de este concepto su fijación en un solo sujeto de opresión, como son las mujeres, lo que dificulta una perspectiva política que comprenda en toda su complejidad el sistema de dominación imperante, donde el capitalismo y el colonialismo son centrales, así como lo es el patriarcado (Escobar \& Kries, 2021; Pérez \& Cisternas, 2021), sin que ello implique abandonar a las mujeres como sujetas políticas. En coherencia con ello, asistimos actualmente a la proliferación de corrientes del feminismo que asumen como ejes la opresión de clase y de raza, herencia de las corrientes feministas radical, negra y marxista de las décadas de 1960 y 1970 que se desarrollaron en los Estados Unidos y algunos países europeos, con una clara definición anticapitalista y anticolonialista. De hecho, el antirracismo fue fundamental para la teorización del sexo como categoría social y política, como vemos, por ejemplo, en el movimiento 
Black Power en los Estados Unidos, en las teorías fraguadas en movimientos de descolonización, como las de Fanon y Memmi en Europa, y en los trabajos sobre sexismo y racismo de la feminista radical Collette Guillaumin en Francia que, entre otros, influyeron en forma decisiva en la militancia feminista radical (Puleo, 2005).

En el debate del Simposio aparece la inquietud por la masificación del enfoque de género en reemplazo del feminismo, y su reducción de la subordinación de las mujeres a roles, divisiones y estratificaciones sociales marcadas por el sexo y desconectadas de la dimensión estructural de la opresión de las mujeres y de la función que cumple en la mantención del sistema. En otras palabras, al repetir el género como consigna y ocuparlo como técnica, olvidamos interrogar las causas de la subordinación. El carácter radical del feminismo, así como su praxis, profundamente imbricada con la experiencia original de las mujeres, se desterró de la academia, lo que podemos comprobar, entre otras cosas, en la ausencia de ciertas corrientes y enfoques teóricos del feminismo en la formación universitaria de pre y posgrado, como por ejemplo, el feminismo popular, radical y marxista.

El género es una teoría colonial, en el sentido que impone una interpretación de la organización social sexuada de cualquier pueblo o sociedad, basada en el modelo occidental moderno y eurocentrado, el cual se rige por lógicas binarias que tienen su correlato en las jerarquías sexuales, de género y de raza, y que, al ser representaciones unilaterales, dejan en el vacío simbólico a las mujeres de color, indígenas o "no blancas". En palabras de Lugones (2008):

Dada la construcción de las categorías, la intersección interpreta erróneamente a las mujeres de color. En la intersección entre 'mujer' y 'negro' hay una ausen- cia donde debería estar la mujer negra precisamente porque ni 'mujer' ni 'negro' la incluyen. La intersección nos muestra un vacío. (p.82)

En el Foro/debate se señaló en tono autocrítico la frecuente utilización del género para dar por hecho el sometimiento de mujeres pobladoras, indígenas o de condiciones sociales precarizadas, lo que revela una actitud mesiánica, que otorga el poder de decidir lo que supuestamente necesitan esas mujeres y que minimiza la interpretación que ellas mismas hacen de su realidad. En el caso de las mujeres mapuche, el análisis de género suele ser reduccionista y obviar el carácter estructural de la violencia que las aqueja como mujeres y como pueblo, como señala una de las participantes del Simposio:

La historia cruza, o sea, cuando una quiere entender una situación de violencia creo que es importante no caer en la reducción que esto es un tema [de] pareja nada más. Yo creo que cuando hablamos de cuerpo, hablamos de territorio. (Araya, Escobar \& Santana, 2021, p. 140) ${ }^{3}$

En esta misma línea, se señala que la relación entre mujeres que tienen distinta posición social -como lo es entre una antropóloga feminista y las mujeres de comunidades con las que realiza su trabajo- es una relación de poder, a veces invisibilizada por idealizaciones o por el mal uso de algunos conceptos feministas como, por ejemplo, el de sororidad. En palabras de una participante del Foro/debate:

Esta cosa amorosa que todas hablemos, quejarnos, reunirnos, a mí personalmente me hace cero sentido, porque finalmente es efectivo que cuando una visualiza sus realidades y nosotras que las que aquí estamos tenemos muy pocas posibilidades de hablar. Yo me voy a posicionar en el camino de buscar volver a ser una mujer mapuche, difícilmente nosotras vamos a poder exponer cuál es la realidad de nuestras herma- 
nas, la real, la que no sé si aparece en los libros, en ninguno de los espacios eventualmente que estamos, por mucha investigación que hagamos, por mucho trabajo de campo, incluso uno como participante, como parte de ese pueblo. (Araya et al., 2021, p. 140)

Uno de los conceptos clave del feminismo, utilizado en el marco teórico del enfoque de género, es el patriarcado, un sistema de dominación histórico y culturalmente específico, definido desde un marco occidental y que tendría una presencia universal, incluso en sociedades originarias, aunque no hay consenso sobre ello. Autoras como Rita Segato (2013) hablan de un patriarcado de baja intensidad y, otras, como Aura Cumes, cuestionan el concepto mismo de patriarcado para interpretar la historia de los pueblos indígenas, así como la existencia de un sistema patriarcal equiparable al occidental para explicar la relación entre los sexos en esas sociedades (Gil \& Cumes, 2021). En general, se coincide en que las formas de ser mujeres $\mathrm{u}$ hombres en comunidades indígenas son inseparables de otras opresiones, derivadas de la dependencia estructural colonial y el capitalismo en su forma extractivista.

En la reflexión colectiva motivada por una de las ponencias presentadas en el Simposio sobre una experiencia etnográfica en Tarapacá con mujeres aymaras (Pérez, 2021), se reconoce que hay una tendencia a suponer a priori la subordinación y la victimización histórica de las mujeres en sociedades indígenas al interpretar sus realidades desde referentes occidentales, así como también a idealizar a los pueblos indígenas como culturas inmutables, obviando su protagonismo en los propios procesos históricos. En palabras de una de las participantes del Foro/debate:
Hay hermanas mapuche nuestras que no están en este espacio, no porque no quieran, capaz porque no les interesa, y ahí también hay una reflexión nuestra, ¿no? Pero en algunas experiencias es porque no pueden no más, porque salir de sus casas significa que eventualmente sus hijos, hijas sean abusadas sexualmente o maltratadas, y también desde ahí desromantizar nuestro propio pueblo también. (Araya, et al., 2021, p. 138)

La institucionalización del feminismo a través de la incorporación del género provoca expectativas en relación con la posibilidad de aportar a la liberación de las mujeres y a los cambios sociales que afecten al modelo social hegemónico. De allí que la participación de las antropólogas y otras cientistas sociales feministas en la academia y en el Estado sea incómoda, vivida como una escisión entre el rol profesional/ laboral y el activista. La doble identidad de las antropólogas como trabajadoras y feministas imprime al ejercicio laboral una tensión permanente que oscila entre la voluntad de aprovechar las herramientas que el propio espacio laboral ofrece, aunque sea en un marco limitado, y la intencionalidad política radical que se asume con el feminismo.

Se discute así la potencialidad política de los espacios institucionales y el considerar como avances medidas puntuales y reformas que ofrecen pequeños cambios en la situación de las mujeres. Así lo expresa una de las participantes del debate del segundo bloque: “ ¿Crees que se puede considerar ganado cuando lo que hemos trabajado como feministas anticapitalistas el Estado lo adapta hacia el capitalismo? El Estado le responde al capital. Entonces no es como algo que se pueda considerar ganado" (Araya et al., 2021, p. 63). En coherencia con esta reflexión, se reivindica una antropología que se defina claramente al servicio de las 
comunidades y que señale la atención crítica que debe ponerse en las implicancias del compromiso con las entidades financiadoras.

Respecto al lugar desde donde nos posicionamos las antropólogas feministas, las participantes del Simposio se preguntaron: ¿qué somos primero, trabajadoras, antropólogas o feministas? Como antropólogas, se interpela la posibilidad de transformar la realidad que se interviene a través del ejercicio de la disciplina si se considera la posición de poder de la investigadora y trabajadora como representante de una institución y poseedora de recursos materiales y simbólicos- con los que las sujetas con las que se trabaja no cuentan. Por otro lado, como feministas, las inquietudes apuntan a reconocer que todo movimiento social y político que aspire a generar un proceso de transformación social profundo necesita ser autónomo.

En el debate del segundo bloque del Simposio se propuso que, ante todo, somos feministas y que, al desarrollar nuestro trabajo le estamos imprimiendo nuestras posiciones políticas, por lo tanto, estas serían categorías indivisibles:

Creo que el cuestionamiento constante, sobre todo en este simposio anticapitalista decolonial, es en qué momento nuestras investigaciones, con harto contenido político, de investigación con historias de vida, que incluyen cosas vitales, cuando llegan a proyectos del Estado se vuelven minimizados. Mi reflexión sobre lo que preguntaban antes, ¿qué somos primero?, ¿somos trabajadoras, somos antropólogas, cientistas sociales, feministas, somos mujeres?, si no nos consideramos feministas, ¿somos madres, hermanas, etc.? (Araya et al., 2021, p. 62)

En la crítica a la fragmentación de nuestro ser humanas que nos sitúa en posiciones estáticas y divididas como mujeres/feministas/ antropólogas, en el Foro/panel emergieron nuevas visiones que reniegan de las etiquetas y apuestan a un reconocimiento de nuestra posición como personas con precariedades similares.

La academia, como espacio de desarrollo profesional para las antropólogas y otras trabajadoras de las ciencias sociales feministas, presenta varias barreras pese a que se ha aceptado en general, e incluso se exige, la incorporación del género como herramienta técnica y formativa. Sin embargo, no se legitima la fuente primera del conocimiento en esta materia, que es construido fuera de la academia, en el activismo, una experiencia que resulta fundamental en la formación de quienes no tienen una comprensión íntima y política de lo que implica el género. Sobre esto se reflexiona en una ponencia presentada en el Simposio:

[...] la negación de la práctica teórica y política de sujetas no académicas, como referentes del movimiento social, de mujeres o de feministas, mujeres pobladoras, defensoras de la tierra, defensoras de derechos humanos, cuya lucha no se restringe a visibilizar la desigualdad entre géneros, sino que va más allá, a evidenciar la desigualdad de un entramado de poder que tiene varias aristas. (Pérez \& Cisternas, 2021, p. 76)

Respecto a los contenidos feministas que se incluyen en la academia, habría una resistencia de parte de las casas de estudio a facilitar el desarrollo de perspectivas críticas, siendo común el rechazo de trabajos y tesis cuando estas adoptan enfoques considerados radicales o "muy" activistas. Por otro lado, se detecta una inadecuada preparación de algunas(os) docentes, que no se explica solo por la falta de estudio sino, como se dijo anteriormente, por una desconexión con la práctica política feminista, que es la sustancia de este conocimiento. Finalmente, la institución universitaria 
asume el desafío a medias, pues no se encarga de entregar una formación feminista real que no solo se quede en lo teórico y técnico, sino que genere cambios concretos, como por ejemplo, en algo tan cotidiano como es la violencia contra las mujeres y la violencia de género que se reproduce al interior de la misma comunidad universitaria.

Siguiendo en el ámbito académico, las participantes de este espacio relataron lo que fue el denominado "mayo feminista", expresión masiva reconocida como un hito de las movilizaciones feministas a nivel mundial y donde se debatieron apasionadamente, en la intimidad de las colectivas, asambleas y "tomas" de los establecimientos, posicionamientos políticos respecto a nudos que atraviesan actualmente al movimiento 4 . La violencia sexual, en particular el acoso, ha sido la expresión más denunciada en los últimos tiempos por parte de mujeres jóvenes en el ámbito universitario y fue el centro de las movilizaciones de 2018.

Este hito fue un laboratorio social donde las jóvenes ejercitaron otras formas de hacer política, recogiendo la experiencia de las movilizaciones estudiantiles de 2006 , que ya venían marcando distancia con antiguas prácticas partidarias, y del modo de las feministas para politizar la experiencia corporizada, cuya memoria se encuentra en los grupos de autoconciencia -"esa es nuestra forma de hacer política" (Librería de Mujeres de Milán, 2004)-, en los cuales las feministas de la década de 1970 construyeron conocimiento situado sobre la sexualidad, el cuerpo y la violencia ${ }^{5}$. Este movimiento influyó también en las escuelas de antropología, producto de lo cual se creó en Santiago una organización de antropólogas, arqueólogas y conservadoras, espacio que se plegó a la iniciativa de recibir testimonios de violencia sexual y acoso, lo que se convirtió en una verdadera avalancha que no supieron cómo enfrentar. En palabras de una participante del debate del tercer bloque:

[...] nos van a mandar una metodología que es para tratar la mesa de testimonios, que son los testimonios de cada una de las mujeres que han sido víctimas de acoso sexual y laboral en distintas experiencias del mundo antropológico y cómo efectivamente poder tratar esos temas. Porque también algo muy importante es reconocer que no tenemos la capacidad de cómo abordarlo, porque no tenemos las herramientas ni metodológicas, ni de ningún tipo, porque en general no somos psicólogas para tratarlo tampoco. Lo que podemos hacer es escuchar, contener y tratar de encausarlo por alguna vía donde se pueda solucionar, pero también tener conciencia de que el sistema judicial no está dando respuesta. (Araya et al., 2021, p. 125)

Esta sensación de incapacidad para responder a la violencia contra las mujeres es muy decidor sobre la situación del feminismo de las actuales generaciones, ya que un problema social, cultural y político se está pensando en los mismos términos que lo hace la institucionalidad, que lo reduce a un asunto psicológico y jurídico. Si bien la desnaturalización del acoso sexual en la academia fue un aporte fundamental de este movimiento, reforzó, al mismo tiempo, la institucionalización del feminismo al poner énfasis en la "judicialización" del acoso, sin lograr conectarlo con el sistema de opresión que lo sustenta, el cual abusa y explota de muchas otras maneras a las mujeres que están fuera de la educación universitaria.

Por otro lado, la dinámica expropiadora de los procesos de institucionalización tradujo la poderosa movilización de mayo de 2018 en dispositivos, mecanismos administrativos y burocráticos, en la forma de direcciones, depar- 
tamentos, programas y protocolos de igualdad y equidad de género, que siguieron centrándose en la violencia contra las mujeres desde un enfoque reduccionista. Entre las participantes del Simposio que fueron protagonistas del momento histórico se aprecia inconformidad con los alcances de esta experiencia política, como se expresa en el debate del primer bloque:

\footnotetext{
Porque si nos dedicamos a resolver estos casos, nos dedicamos solo a eso, porque hay una cantidad de abusos y de acoso de todo tipo, laboral, sexual, enorme. Entonces el movimiento feminista se podría quedar solamente anclado a eso y no lo va a lograr. Yo creo que no es la manera apropiada de abordarlo, porque no podemos dejar todas las otras cuestiones que son también políticamente relevantes de lado, para hacernos cargo solamente del acoso. Yo no digo que hay que dejarlo de lado, pero digo que no podemos centrar toda nuestra acción política en eso. (Araya et al., 2021, p. 126)
}

La relación entre Estado, feminismo y enfoque de género aparece en el debate referida principalmente a las tensiones que este ámbito laboral nos plantea a las antropólogas, pero no se aprecia interés por el Estado mismo como objeto de estudio, solo se hacen menciones tangenciales a aspectos abordados por la antropología feminista que, según Moore (2009), lo ha desarrollado en al menos cuatro enfoques ${ }^{6}$.

Otro aspecto cuestionado sobre los efectos de la institucionalización del feminismo en el Estado es la lógica perversa que obliga a las organizaciones de mujeres a competir por los recursos -lo que se aplica a toda organización social-, lo que incentiva la fragmentación del movimiento social y un actuar bajo la lógica del "proyectismo", desfavorable a la generación de procesos que apunten a cambios sustantivos de la realidad social. Desde otra perspec- tiva, se identifican también efectos positivos de la transversalidad del género en el Estado, especialmente en las comunidades como, por ejemplo, el uso de lenguaje que visibiliza a las mujeres o la exigencia de incluir ciertos criterios de equidad en las políticas públicas que han hecho posible la generación de reformas. Sin embargo, se apela a una actitud crítica frente a la integración del feminismo y se plantean algunas interrogantes, como señala una de las participantes del segundo bloque de debate: "¿qué ha logrado el feminismo con la incorporación del género en el Estado?, ¿qué hemos hecho las antropólogas que alguna vez hemos trabajado en el Estado para que se mueva a un lugar deseable para la liberación de las mujeres?" (Araya et al., 2021, p. 58).

\section{Construcción de conocimientos}

\section{en el feminismo}

Un nudo central de la antropología feminista que se evidenció en el Simposio se vincula con la construcción de conocimientos. Por una parte, se profundiza en la crítica a la academia formal $y$, por otra, se plantea la necesaria construcción de conocimientos colectivos vinculada al movimiento feminista y con un claro horizonte de transformación social.

Junto a la crítica a la despolitización que ha generado la incorporación del género en la academia, también ha sido cuestionada por las antropólogas feministas la elaboración de conocimientos de manera individual que se realiza en la academia, forma vinculada a una "capitalización individual" que se aleja de la construcción de saberes colectivos característica del movimiento feminista a lo largo de su historia. 
La supuesta "neutralidad" de las ciencias en la academia formal y su desvinculación de las necesarias transformaciones sociopolíticas es otro aspecto que ha sido analizado críticamente por las antropólogas feministas. A diferencia de países de Abya Yala, como Argentina o Brasil, donde algunos sectores de la academia se vinculan estrechamente a los movimientos sociales desde el reconocimiento de los saberes diversos y la colaboración, en Chile observamos una distancia de esta del quehacer de las organizaciones sociales y del pensamiento crítico. Esta tendencia se vincula al contexto social y político de la posdictadura en Chile, donde los movimientos sociales y el pensamiento crítico se repliegan en la década de 1990 y 2000 y vuelven a levantarse posteriormente en las grandes movilizaciones del movimiento estudiantil de 2006 y 2011 y en el movimiento feminista en sus campañas por el aborto, contra la violencia machista y el mayo feminista de 2018.

La crítica feminista a la anhelada "neutralidad" de la academia se entronca con los planteamientos iniciales de la epistemología feminista en la década de 1970. El reconocimiento de la ciencia como resultado de consensos de comunidades científicas en contextos culturales específicos -hombres de clase alta- permitió reconocer el carácter androcentrista y de clase del conocimiento científico ya en los primeros escritos de las epistemólogas feministas (Hartsock, 1983; Harding, 1987). La crítica radical de la epistemología feminista en este período cuestiona también la objetividad, la racionalidad y la universalidad de las ciencias desde el análisis crítico de la supuesta distancia entre "objeto" y "sujeto" en la investigación científica.
Los enfoques epistemológicos feministas de esa etapa (Longino, 1993; Haraway, 1995; Harding, 1996) -el punto de vista feminista, la objetividad fuerte, el empirismo feminista, el conocimiento situado, entre otros-, que fueron ampliamente desarrollados durante las décadas de 1980 y 1990 en los Estados Unidos, tienen eco en Chile con los planteamientos de Julieta Kirkwood, Ximena Bunster, Edda Gaviola, entre otras. Este cuestionamiento a las ciencias sociales en particular se debilita en las décadas de 1990 y 2000, en el contexto del repliegue político e ideológico, y reemerge con fuerza en las nuevas generaciones de historiadoras y antropólogas feministas en la actualidad.

Este resurgimiento de la crítica epistemológica radical que compartimos las antropólogas feministas se ha encontrado con los cuestionamientos del feminismo decolonial, desde donde se hace también una crítica epistemológica contra la lectura sociocientífica y objetivante de las ciencias (Lugones, 2008; Curiel, 2014; Espinosa, 2018).

Por otra parte, nuestros debates como antropólogas feministas ponen énfasis en una cuestión central: la construcción de conocimientos desde el activismo político feminista. El reconocimiento del saber feminista históricamente enraizado en su movimiento o en una imbricada vinculación entre academia y movimiento nos hace preguntarnos por las claves para repensar un conocimiento crítico, riguroso y politizado. Una cuestión fundamental es posicionar al feminismo no solo como una crítica teórica, sino como una práctica política en torno a una propuesta autónoma (Curiel, 2017). En este sentido, la construcción de conocimientos feministas no puede generarse desde un saber académico de "género" desvin- 
culado de un quehacer político concreto dentro del movimiento feminista.

El activismo feminista no solo implica un quehacer militante, sino también transformaciones concretas en lo personal y profesional, en las formas que nos planteamos la investigación antropológica y la relación con las mujeres con que interactuamos. Una cuestión central, como plantea Ochi Curiel (2017), es reconocer que las prácticas políticas producen conocimiento, saberes que se construyen de formas colectivas, y que las sujetas subalternizadas producen conocimientos desde sus comunidades. El feminismo y, en particular, la antropología feminista requieren legitimar el conocimiento cotidiano, el saber de las comunidades y de los movimientos subalternos, que deben ser reconocidos como conocimientos válidos. Como plantea una expositora del Simposio:

[...] la propuesta de involucrar a investigador e investigado/a en todo el proceso de la investigación parece ser un aspecto fundamental para lograr la pretensión holística de la disciplina. Así, para la investigadora como para el/la investigado/a, cuando se enfoca desde una perspectiva feminista y decolonial, el estudio antropológico se presenta como un espacio de construcción y participación en torno al cambio social. (Ibarra, 2021, p. 99)

Desde el feminismo decolonial, María Lugones (2008) sostiene que contra el enfoque científico y objetivante es necesario comprender la subjetividad activa, emprender la búsqueda del locus fracturado en la resistencia a la colonialidad del género. Lugones retoma el "pensamiento de frontera" de Mignolo (2011) para proponer un pensamiento de frontera feminista que coloca en un lugar central la colonialidad del género y el rechazo, la resistencia, y la respuesta de las subalternas(os).
Otra cuestión central que se propone la construcción de conocimientos desde el feminismo decolonial es la necesidad de "desengancharse" de las categorías modernas como democracia, Estado moderno, etc., para validar otras formas de entender del mundo (Curiel, 2017). En una comprensión aún más compleja y descolonizada de la realidad social, Yuderkys Espinosa (2018) propone las ontologías relacionales -que reconocen a los seres vivos y no vivos y la relación no jerárquica entre todos ellos- en la comprensión de la realidad social.

Por otra parte, la creciente ampliación de una "oferta académica" de estudios de posgrado en género en las universidades también ha generado análisis críticos desde la antropología feminista (Pérez \& Cisternas, 2021). Se evidencia así que la construcción colectiva de conocimientos que ha caracterizado la elaboración teórico-analítica del feminismo no se observa en estas propuestas académicas, en donde se sigue relevando la construcción individual de conocimientos, sin propuestas epistemológicas, metodológicas y políticas críticas que permitan subvertir las lógicas positivistas y de mercado, y el "extractivismo académico" que caracteriza a la investigación social científica:

[...] consideramos que el conocimiento que es producido con base en estas sujetas no es compartido, difundido, a las distintas comunidades y se mantiene como un capital cultural para un grupo privilegiado en pos de mantener ese privilegio como es la comunidad científica y académica. Por último, si esos intereses y preocupaciones de estudio no se proyectan fuera de la academia con una práctica y acción política que le de coherencia y consecuencia a esos intereses, se recae en una práctica colonial que representa el saber-poder de un grupo por sobre otro, a través de su instrumentalización. (Pérez \& Cisternas, 2021, p. 75) 
Las propuestas académicas que han incorporado el feminismo decolonial lo han hecho desde enfoques que replican las formas tradicionales de la academia y no generan nuevas apuestas de prácticas pedagógicas que se propongan, por ejemplo, la vinculación con el movimiento feminista o con los territorios y comunidades (Pérez \& Cisternas, 2021).

Desde nuestra perspectiva, estos énfasis de los estudios de posgrado en género son parte de los procesos de burocratización y despolitización del feminismo en las instituciones que vienen instalándose hace varias décadas en Chile. La ampliación de un feminismo decolonial académico en Abya Yala ha sido cuestionada por su alejamiento de las prácticas feministas concretas. Como plantea Curiel (2017), este enfoque academicista sintetiza las ideas fuerza de un movimiento eminentemente teórico-político, que no puede sino constituir su reflexividad al calor del accionar político feminista.

Otra reflexión importante que emerge del quehacer de las antropólogas feministas en el Simposio, se pregunta por nuestro posicionamiento en el trabajo etnográfico. Desde nuestra perspectiva es relevante retomar los enfoques de la etnografía feminista que, desde hace varias décadas atrás, cuestionó el positivismo prevaleciente en la etnografía convencional, fundamentalmente el androcentrismo y la supuesta neutralidad del conocimiento etnográfico (Castañeda, 2012). Nos parece relevante que el trabajo etnográfico actual preste atención a la crítica que la etnografía feminista ha realizado al androcentrismo presente en la disciplina: la consideración principalmente de los hombres como informantes clave, la legitimación del punto de vista masculino y la invisibilización y deslegitimación del quehacer de las mujeres, relegadas a un ámbito doméstico interpretado sin poder (Reiter, 1975 y Comas, 1995, citados en Martin, 2008).

La supuesta neutralidad de la etnografía clásica es cuestionada desde la etnografía feminista para asumir una postura clara a favor de los grupos subordinados. Como señala Wazir Jahan Karim (citada en Castañeda, 2012), el interés por la experiencia de una vasta gama de sujetos y sujetas pasa de ser una disciplina fundamentalmente descriptiva a una sustentada en una escritura política de la cultura, toda vez que se convierte en una disciplina involucrada/ comprometida con la vida de las minorías. El pensamiento de frontera feminista (Lugones, 2008) permite colocar a las mujeres en los lugares de la rebeldía, de la transgresión, de la resistencia y de la emergencia, lugares en los que se gesta la contrahegemonía espontánea del malestar con la cultura naturalizada, lo que explicita el carácter político de la etnografía feminista (Castañeda, 2012).

El desafío de la etnografía feminista, entonces, consiste en elaborar explicaciones e interpretaciones culturales que partan de las mujeres colocadas en determinados contextos de interacción, posicionándolas no solo como informantes sino como creadoras culturales (Castañeda, 2012). Además, los cruces con la etnografía del sujeto(a) y la autoetnografía han permitido no solo "dar voz" a las mujeres sujetas de los estudios, sino también el ejercicio de "darnos la voz" a nosotras mismas como etnógrafas en un ámbito disciplinario que aún nos margina.

Una cuestión central vinculada a los cuestionamientos críticos de la etnografía feminista es la relevancia que asume el pensamiento decolo- 
nial en la antropología feminista. La convocatoria al Simposio en el Congreso Chileno de Antropología se enmarcó en este enfoque teórico-político y generó una importante participación de antropólogas feministas que reflexionamos, analizamos e investigamos incorporando las reflexiones del feminismo decolonial. La crítica a nuestra formación como antropólogas y la autocrítica a nuestras prácticas profesionales y políticas en el trabajo feminista con mujeres evidencia el colonialismo como un elemento central. Como señalan Jofré y Salazar:

\footnotetext{
Dado que el colonialismo está presente en nuestras prácticas antropológicas y feministas, ha sido necesario crear instancias propias de autoformación e investigación que nos permitan ampliar y explorar profundamente las implicancias epistemológicas que nos mantienen en un colonialismo del saber y en un racismo epistémico. Desde este posicionamiento surge la posibilidad de un feminismo descolonial que pretende superar las convenciones clásicas sobre género y sexualidad -o lo que Yuderkys Espinosa (2016) Ilama "razón eurocentrada del feminismo"- lo que en nuestros contextos se manifiesta en un activismo político materializado en GAFPA. (2021, p. 71) ${ }^{7}$
}

El pensamiento feminista decolonial nos ha permitido evidenciar nuestras propias prácticas coloniales y explorar formatos individuales y colectivos que nos permitan generar formas diferentes de investigación y vinculación con las sujetas. La crítica a las prácticas academicistas desde el feminismo decolonial, como ya se ha evidenciado (Curiel, 2017; Jofré \& Salazar, 2021), nos invita a mirar más allá de las perspectivas poscoloniales o decoloniales, y avanzar, como señala Silvia Rivera Cusicanqui, hacia un quehacer anticolonial.

Otro elemento relevante en la construcción de conocimientos antropológicos feministas que emergió en el Simposio es la reinstalación de lo sentipensante: la necesaria vinculación entre la razón, la subjetividad y las emociones para poder comprender y analizar la realidad que estamos estudiando. Desde nuestra perspectiva, esta concepción -que se retoma del pensamiento crítico de Abya Yala, particularmente de Fals Borda- se vincula a la noción feminista de los años setenta de "lo personal es político", en el sentido de que plantea la necesaria vinculación de los ámbitos privado y público, de los sentires y la racionalidad. Es relevante que esta noción difundida por Kate Millet (1995 [1970]), pero que condensa las reflexiones políticas de la época, siga formando parte sustantiva del movimiento feminista y también de las reflexiones colectivas y las investigaciones de las jóvenes antropólogas feministas que participaron en el Simposio.

De esta forma, los enfoques de la antropología feminista, reposicionan una idea fuerza central del feminismo: la indisoluble relación de nuestro pensar y sentir, en una apuesta que vincula también lo personal y lo político, lo profesional y lo político. Estos múltiples encuentros e imbricaciones de dimensiones de la vida social nos muestran que las extendidas dicotomías y la imposición radical de la razón moderna son cuestionadas de manera importante en el quehacer de las antropólogas feministas.

\section{A modo de reflexiones finales}

La importante recepción que tuvo la convocatoria del Simposio "Antropología feminista en clave decolonial y anticapitalista: sembrando vinculaciones entre academia y movimiento" nos ha permitido obtener una panorámica y dialogar con las posiciones teóricas y políticas que predominan actualmente en este grupo 
de antropólogas feministas en Chile. También nos muestra que la militancia feminista es parte fundamental del quehacer profesional de las convocadas.

Los ejes del debate -mujeres como sujetas, construcción de conocimientos y relación con el Estado- evidencian las coordenadas de nuestro quehacer como antropólogas feministas, en el que los trabajos sobre el Estado concitaron escaso interés, aunque no un menor cuestionamiento durante el encuentro. Se reposicionan tensiones siempre presentes en la antropología en cuanto a la relación entre investigador(a) y las personas o comunidades que son estudiadas, y la validación de formas de conocimientos no académicos, evidenciando el lugar que hoy en día ocupan estas reflexiones para quienes realizamos un trabajo directo e involucrado con otras mujeres. Se cuestiona fuertemente la construcción de conocimiento feminista alejado de una práctica política en los territorios, en coherencia con los postulados del feminismo decolonial, radical y anticapitalista, que guiaron el Simposio. La crítica radical al enfoque de género, el cuestionamiento a la fragmentación de nuestra posición como humanas, feministas, mujeres, antropólogas y su compleja imbricación, junto a una profunda crítica a la academia, son cuestiones que también orientan nuestro quehacer.

Un aspecto que atravesó el Simposio fue la crítica al enfoque de género como construcción teórica y su incidencia política. Si bien se reconoce la utilidad analítica que pudo haber tenido inicialmente, hoy, después de tres décadas de su emergencia, se evidencia como una barrera en el ejercicio de una antropología comprometida con la transformación social.
Atendiendo a la búsqueda del feminismo generar un cambio estructural en la sociedad donde las mujeres seamos reconocidas como creadoras culturales y sujetas históricas-, el enfoque de género tal como está siendo aplicado en el Estado y la academia, no se ha orientado en esa dirección y se ha vuelto una herramienta técnica vaciada de contenido político.

Para las antropólogas feministas de estas generaciones, el género concurre en distorsiones respecto a su referente, el feminismo. Se observa un reduccionismo al generar medidas o mecanismos estandarizados y orientados hacia la eficiencia, centrados en objetivos medibles que no permiten impulsar procesos de cambio. El escenario institucional genera tensiones y dilemas para las antropólogas feministas que se reflejan fuertemente en la relación con las sujetas de estudio o de intervención pública con quienes planteamos la necesidad de establecer una relación transparente, desde el reconocimiento de la desigualdad entre las partes y la aceptación de la posibilidad de negociación.

El énfasis en el enfoque de género al interior del movimiento feminista ha invisibilizado cuestiones centrales en la vida de mujeres de sectores subalternos, donde el ser mujer está profundamente imbricado con otras posiciones de subordinación.

La crítica radical del feminismo decolonial al binarismo y el colonialismo del género, se ve profundizada por un cuestionamiento basado en el quehacer concreto de intervención e investigación antropológica y en el activismo político feminista. Esta crítica ampliada nos permite preguntarnos por la historicidad y la politicidad de las categorías analíticas que se generan, debilitan y transforman en la teoría 
feminista. Al parecer, la creciente incidencia de los feminismos de Abya Yala -decolonial, indígena, comunitario- está aportando otras claves analíticas que son necesarias revisar y aprehender en una práctica antropológica feminista anticolonial.

La profunda y extendida crítica a las formas académicas tradicionales de generación de conocimientos desde la antropología feminista con la que hemos dialogado coloca un acento central en la urgencia de generar saberes colectivos desde las prácticas concretas feministas. La deslegitimación de un conocimiento aparentemente neutro y despolitizado nos entronca con los postulados de la epistemología feminista de los años setenta y nos obliga a avanzar en formas nuevas de repensar los saberes, actualizando también viejas prácticas y estrategias de investigación sumergidas por el largo período de desmovilización en el Chile de la posdictadura.

Sostenemos que la etnografía feminista -con su vigente crítica al androcentrismo en nuestra disciplina y el reposicionamiento del lugar de poder de las mujeres en las comunidades y territorios- se vuelve un enfoque central para nuestro quehacer profesional y político como antropólogas feministas.

Finalmente, creemos que el ejercicio de retomar y analizar críticamente las reflexiones individuales y colectivas de un Simposio disciplinario para develar los cuestionamientos y nudos comunes es parte del desafío de apostar a la generación colectiva de conocimientos que ha caracterizado a la construcción teórica del feminismo. Las reflexiones que emergen desde el quehacer concreto de las antropólogas feministas en el contexto actual construyen un conocimiento situado que va generando un sustrato reflexivo y analítico. Este ejercicio de partir de la práctica antropológica, desde diversos espacios no solo académicos, sino también organizativos y políticos, descentra la construcción del conocimiento de la academia y la reposiciona en las sujetas colectivas que actuamos, estudiamos y generamos saberes desde los movimientos feministas. Consolidar estas formas de construcción de conocimientos nos permitirá prescindir de las "autoridades intelectuales" y dar voz a lo que investigamos, pensamos y sentimos desde lo colectivo.

Las inquietudes y reflexiones compartidas en el Simposio no estaban aún permeadas por las circunstancias sociales que nos atraviesan al momento de escribir este ensayo, marcadas por una revuelta popular que ha inspirado a otros pueblos latinoamericanos y una crisis sanitaria mundial. En este contexto difícil por el recrudecimiento de la represión y la sofisticación del control y la vigilancia, han revivido antiguas prácticas solidarias y colectivas de subsistencia y se han creado otras que ubican en el centro la vida, la comunidad y la transmisión de saberes y prácticas entre las personas y el espacio territorial. En este proceso, las mujeres somos protagónicas, no solo como cuidadoras o sustentadoras de la vida comunitaria, sino también como sujetas activas creadoras de nuevos modos de vida. Este escenario abre nuevas preguntas y desafíos a una antropología feminista comprometida que refuerzan el análisis aquí compartido. 


\section{Notas}

${ }^{1}$ Desde el feminismo comunitario e indígena, así como desde el pensamiento decolonial, se ha desarrollado una importante reflexión crítica sobre el sujeto político del feminismo, en el que se cuestiona que sea solo la mujer y esta bajo un modelo definido por el paradigma moderno (para profundizar consultar a las autoras Ochy Curiel, María Lugones, Lorena Cabnal, Francesca Gargallo, Aura Cumes, entre otras). Por otro lado, desde el movimiento queer y de la diversidad sexual, así como desde algunos sectores del lesbofeminismo y el feminismo liberal, se cuestiona el carácter fijo e inmutable del sexo y de la mujer como categoría biológica (para profundizar, consultar a las autoras Beatriz Preciado, Judith Butler, Sayak Valencia, entre otras). Por su parte, desde el feminismo radical, radical de la diferencia y de la igualdad, se fundamenta que la opresión contra las mujeres está basada en el sexo como categoría biológica, además de ser ellas el sujeto político del feminismo (para profundizar, consultar a las autoras María Milagros Rivera, Andrea Franulic, Sheila Jeffreys, Victoria Sendón de León, entre otras).

${ }^{2}$ Los conceptos de identidad de género, orientación sexual y expresión de género fueron adoptados en políticas públicas sobre violencia contra las mujeres, por ejemplo, en el documento "Orientaciones técnicas de prevención social sobre sensibilización y prevención de la violencia contra las mujeres en contexto de pareja" (Ministerio del Interior y Seguridad Pública, 2020). Los conceptos de igualdad y equidad de género, que no apuntan a la transformación estructural de la condición de las mujeres, sino solo a incorporarlas en igualdad con los hombres al sistema imperante, son también el hilo conductor de la política pública del Ministerio de la Mujer y la Equidad de Género.

${ }^{3}$ Estos textos dan cuenta de los debates en los tres bloques del

\section{Referencias bibliográficas}

Araya, T., Escobar, A. \& Santana, P. (Comps.). (2021). Antropología feminista en clave decolonial y anticapitalista: Sembrando vinculaciones entre academia y movimiento. Publicación virtual.

Castañeda, M. (2012). Etnografía feminista. En Blázquez, N., Flores, F. \& Ríos, M. (Coords.), Investigación feminista. Epistemología, metodología y representaciones sociales. México: UNAM.

Curiel, O. (2014). Hacia la construcción de un feminismo descolonizado. En Espinosa, Y., Gómez, D. \& Ochoa, K. (Eds.), Tejiendo de otro modo: Feminismos, epistemología y apuestas decoloniales en Abya Yala. Popoyán: Universidad del Cauca.

(2017). Entrevista: las claves de Ochy Curiel. Feminismo decolonial. Recuperado de https://www.youtube.com/ watch? $v=7 Z S H q v K L A N Q \& t=93 \mathrm{~s}$

Escobar, A. \& Kries, S. (2021). El género en cuestión y el "ser social mujer”. En Araya, T., Escobar, A. \& Santana, P. (Comps.) (2021). Antropología feminista en clave decolonial y anticapitalista:
Simposio y en el Foro/debate. Ante la imposibilidad de identificar la autoría, las citamos de acuerdo a las normas solicitadas por esta revista.

${ }^{4}$ Este movimiento comenzó el 17 de abril de 2018 en la Facultad de Humanidades de la Universidad Austral de Chile y posteriormente se extendió a más de 26 casas de estudio en todo el país durante el mes de mayo de ese mismo año.

${ }^{5}$ Entre las décadas de 1970 y 1980 proliferan los grupos de autoconciencia en los que las mujeres comparten sus experiencias más íntimas, exploran y conocen sus cuerpos, y construyen conocimiento y teoría a partir de la experiencia y la práctica política (Mackinnon, 1991). Un trabajo emblemático de este tipo es el realizado por el Colectivo de Mujeres de Boston, Nuestros cuerpos, nuestras vidas, en el año 2000.

${ }^{6}$ Los cuatro enfoques serían: 1) "Aspectos relativos a las ayudas sociales garantizadas por el estado y la manera en que este velaba por la mujer y ejercía control sobre ella", 2) "el aparato ideológico del Estado, es decir, en los medios de comunicación, las escuelas, los partidos políticos, la iglesia y la familia, que contribuyen a consolidar y perpetuar las ideologías dominantes", 3) la "respuesta del Estado ante la labor organizativa de la mujer -a los medios que el Estado utiliza para desorganizar, controlar e institucionalizar las actividades de la mujer, en especial, las organizaciones femeninas populares, y" 4) la "desigual influencia ejercida por hombres y mujeres en la política estatal y en su desigual acceso a los recursos del Estado" (Moore, 2009, p.156).

${ }^{7}$ Grupo de Autoformación Feminista Prudencia Ayala, formado en Santiago en 2017 por feministas antropólogas y personas de otras disciplinas.

sembrando vinculaciones entre academia y movimiento (pp. 102115) Publicación virtual.

Espinosa, Y. (2018). Cuestionar las clasificaciones jerárquicas de la modernidad: Ontologías relacionales y feminismo no eurocentrado. Ciclo de Conferencias: Ecofeminismo Teoría y práctica para aplicar en proyectos de desarrollo. CICODE, Universidad de Granada, 7 de noviembre. Recuperado de https://www.youtube.com/ watch?v=NTM8f5LfetU

Gil, Y. \& Cumes, A. (2021). Entrevista con Aura Cumes: La dualidad complementaria y el Popol Vuj: Patriarcado, capitalismo y despojo. Revista de la Universidad de México, 3, 18-25. Recuperado de https://www.revistadelauniversidad.mx/download/171c2172-9cbe40cc-aef9-df2bc0ae3a0b?filename=entrevista-con-aura-cumes-ladualidad-complementaria-y-el-popol-vuj

Haraway, D. (1995). Ciencia, ciborgs y mujeres: La reinvención de la naturaleza. Madrid: Cátedra. 
Harding, S. (1987). Is there a feminist method? En Harding (Ed.), Feminism and methodology (pp. 162 -164). Bloomington: Indiana University Press. (1996). Ciencia y feminismo. Madrid: Morata.

Hartsock, N. (1983). The feminist standpoint: Developing the ground for a specifically feminist historical materialism. En Harding, S. \& Hintikka, M. B. (Eds.), Discovering reality: Feminist perspectives on metaphysics, epistemology, methodology and philosophy of science (pp. 4-15). Dordrecht: Reidel. Recuperado de https://doi. org/10.1007/0-306-48017-4_15

Ibarra, M. (2021). Metodologías feministas y decoloniales en contextos de diversidad cultural: Hacia una investigación antropológica situada e implicada. En Araya, T., Escobar, A. \& Santana, P. (Comps.), Antropología feminista en clave decolonial y anticapitalista: Sembrando vinculaciones entre academia y movimiento (pp. 89-101). Publicación virtual

Jofré, N. \& Salazar, L. (2021). Porque lo personal es político: ¿Qué sentipensamos como mujeres, antropólogas, feministas y autoformadas? En Araya, Araya, T., Escobar, A. \& Santana, P. (Comps.), Antropología feminista en clave decolonial y anticapitalista: sembrando vinculaciones entre academia y movimiento (pp. 81-88). Publicación virtual.

Librería de Mujeres de Milán (2004). No creas tener derechos. Madrid: Horas y Horas.

Longino, H. (1993). Subjects, power and knowledge: Description and prescription in feminist philosophies of science. En Alcoff, L. \& Potter, E. (Eds.), Feminist epistemology (pp. 101-120). Nueva York: Routledge.

Lugones, M. (2008). Colonialidad y género. Tabula Rasa, 9, 77-101.

MacKinnon, C. (1991). From practice to theory, or what is a white woman anyway? Yale Law Journal 4(13), 13-22. Recuperado de https:// www.medium.com/@feminismoclasse (traducción en portugués).

Martin, A. (2008). Antropología del género: Culturas, mitos y estereotipos sexuales. Madrid: Cátedra, Universitat de Valencia, Instituto de la mujer.
Mignolo, W. (2011). Geopolítica de la sensibilidad y del conocimiento: Sobre (de)colonialidad, pensamiento fronterizo y desobediencia epistémica. Recuperado en https://transversal.at/ transversal/0112/mignolo/es

Millet, K. (1995 [1970]). Política sexual. Madrid: Cátedra

Ministerio del Interior y Seguridad Pública (2020). Orientaciones técnicas de prevención social. Tipología (VCM), sensibilización y prevención de la violencia contra las mujeres en contexto de pareja. Recuperado de http://www.fnsp.gov.cl/media/2021/03/OOTT-2021TIPOLOGIA-VCM.pdf

Moore, H. (2009) Antropología y feminismo (5 $5^{\underline{a}}$ ed). Valencia: Cátedra, Universidad de Valencia, Instituto de la Mujer.

Pérez, C. (2021) Visibilizando representaciones sexistas en el discurso y la práctica de docentes. Etnografía escolar en tres escuelas de la región de Tarapacá. En Araya, T., Escobar, A. \& Santana, P. (Comps.). (2021). Antropología feminista en clave decolonial y anticapitalista: sembrando vinculaciones entre academia y movimiento (pp. 57). Publicación virtual.

Pérez, S. \& Cisternas, N. (2021). Pensarnos en la formación práctica. Reflexiones a partir de la instauración de un nuevo programa de postgrado en estudios de género y feminista. En Araya, T., Escobar, A. \& Santana, P. (Comps.) (2021). Antropología feminista en clave decolonial y anticapitalista: sembrando vinculaciones entre academia y movimiento (pp. 66-80). Publicación virtual

Pisano, M. \& Franulic, A. (2009). Una historia fuera de la historia. Santiago de Chile: Sogol.

Puleo, A. (2005). Lo personal es político, el surgimiento del feminismo radical. Teoría feminista. En de Miguel, A. \& Amorós, C. (Coord). Teoría Feminista. Del feminismo liberal a la posmodernidad (pp. 35 -68). Madrid: Biblioteca Nueva.

Segato, R. (2013). La crítica de la colonialidad en ocho ensayos y una antropología por demanda. Buenos Aires: Prometeo Libros.

Wazir, J. K. (1993). Gendered fields: Women, men and ethnography. Londres: Routledge. 